\title{
Effects of MicroRNAs in Valvular Heart Diseases: From Molecular Pathways to Clinical Effects and Therapeutical Strategies
}

\author{
*Francesco Nappi, $\mathrm{MD}^{1} ;$ *Adelaide Iervolino, $\mathrm{MD}^{2}$; Sanjeet Singh Avtaar Singh, $\mathrm{PhD}, \mathrm{MD}^{3}$; Massimo \\ Chello, $\mathrm{MD}^{4}$ \\ ${ }^{1}$ Department of Cardiac Surgery, Centre Cardiologique du Nord de Saint-Denis, Paris, France. \\ ${ }^{2}$ Department of Cardiovascular Sciences, Fondazione Policlinico Universitario A. Gemelli IRCSS, \\ Rome, Italy \\ ${ }^{3}$ Department of Cardiothoracic Surgery, Golden Jubilee National Hospital, Glasgow, United Kingdom \\ ${ }^{4}$ Cardiovascular surgery, Università Campus Bio-Medico di Roma, 00128, Rome, Italy \\ $†$ Francesco Nappi and Adelaide Iervolino are joint first authors who have contributed equally to the \\ manuscriptt
}

Keywords : miRNAs, valvulopathy, aortic stenosis, calcification, delivery systems

\begin{abstract}
Micro-RNAs have been recently investigated in preclinical and clinical research as regulators of valvulopathies pathogenesis, diagnostic biomarkers and therapeutical targets. Evidences from in-vivo and in-vitro studies demonstrated stimulatory or inhibitory roles in mitral valve prolapse, aortic leaflet fusion and calcification pathways, specifically osteoblastic differentiation and transcription factors modulation. Tissue expression assessment and comparison between physiological and pathological phenotypes or different disease entities, including mitral valve prolapse and mitral chordae tendineae rupture, emerged as the best strategies to address mi-RNAs over or under-representation. In this review we discuss the fundamental intracellular homeostatic and cardiogenetic pathways regulated by mi-RNAs leading to defects in mitral and aortic valves, congenital heart diseases and the possible therapeutical strategies targeting them. Mi-RNAs inhibitors comprise antisense
\end{abstract}


oligonucleotides and sponge vectors while mi-RNA mimics, mi-RNA expression vectors and small molecules are possible practical strategies to increase their activity. Advantages and technical limitations, including instability and complex pharmacokinetics are also presented. Novel strategies, such as nanoparticles and liposomes, are conclusively described to improve knowledge on these molecules delivery and establish future personalized treatment directions.

\section{Cardiovascular diseases and circulating mi-RNAs}

\subsection{Biomarkers in mitral valve prolapse}

MiRNAs have been evaluated in various pathologies including cardiovascular disease, allowing for the exploration of coronary artery disease, cardiomyopathy, myocardial infarction, and aortic valve stenosis, the use of plasma level of miRNAs to monitor degenerative disease of the mitral valve but has not been widely adopted by the cardiological community [1-6]. The resistance of cardiologists to the use of mi-RNAs as biomarkers for assessing mitral valve prolapse (MVP) can be explained, at least in part, by the fact that the clinical benefit of similar investigations for degenerative calcification of stenotic aortic valve [5-9] have been recently affirmed by the degenerative disorders of mitral valve leading to the regurgitation [10-15].

Mitral valve prolapse is a debilitating disease with a worldwide prevalence of $2-3 \%$, both in low- and high-income countries, thus reaching over 176 million affected individuals [16,17]. From a histological point of view, the MVP is distinguished mainly through myxomatous degeneration. In younger patients, the pathoanatomic feature arises from the development of excessive tissue formation on mitral valve leaflets leading to Barlow's syndrome [18]. This condition is the most extreme form of myxomatous degeneration. In contrast, pathoanatomic lesions in older patients with mitral valve prolapse tend to manifest as fibroelastic degeneration rather than excess leaflet tissue. Both forms of the disease can lead to leaflet prolapse and chordal elongation or rupture that depict the type of degenerative mitral-valve disease [19-21]. The change of normal histological features of valvular tissue results in incomplete closure of 
the mitral orifice, causing regurgitation. In addition, annular dilation may develop over time, leading to further advancement in the severity of mitral regurgitation.

A careful evaluation of MVP is achieved with transthoracic echocardiography which serves to determine the mechanism and severity of mitral regurgitation. Although the information provided by echo 2D and 3D yields comprehensive morphological and functional assessment [22-24], the lack of effective medical therapy in slowing the progression of these lesions making surgery the only viable treatment option [25-27]. Recently a new impetus in mitral valve repair has been afforded by the use of the transcatheter approach, although this requires more solid validation of results for wider application [28-30].

The landmark study of Mayeux [1] has highlighted the emergence of biomarkers as an important tool for a better diagnosis, thus, shifting paradigms in clinical practice progression by increasing the possibility of obtaining a definitive prognosis in specific pathological conditions. However, there is currently no likelihood of using specific circulating biomarkers for the identification of mitral valve prolapse in clinical practice.

Regarding MVP, several studies have looked for circumstantial evidence between the presence of biomarkers and the valvular degenerative process. The studies by Songia et al $[10,11]$ investigated the possible association between osteoprotegerin and mitral valve degeneration in Barlow syndrome without recording a specific correlation. The study by Tan et al, which evaluated the presence of biomarkers through proteomics, was in the same direction. The authors reported higher levels of haptoglobin, platelet basic protein, and complement component $\mathrm{C} 4 \mathrm{~b}$ in individuals with degenerative mitral valve prolapse [12]. The results were not conclusive for a specific correlation between biomarkers and disease development. 


\subsection{Emerging differences in mi-RNAs as biomarkers in stenotic or insufficient valvulopathy}

MicroRNAs (miRNAs) have emerged as circulating biomarkers encoding a new category of potential molecules to study. Almost 20 years ago, a study of the eukaryotic genome reported 20-30 nucleotide RNA molecules emerging with the function of playing a critical regulatory role in the expression and function of eukaryotic genomes. Carthew et al [31] investigated the role of two leading classes of these small RNAs with specific regulatory functions leading to direct implications in the fundamental processes of biology, as well as in the aetiology and treatment of the disease. The authors identified short interfering RNAs (siRNAs) and microRNAs (miRNAs) a pivotal role in intervening on both somatic and germ lines alongside a wide range of eukaryotic species. The specific target of siRNA and miRNA were the sentinels of the genome in defence of invasive nucleic acids, through the ability to negatively regulate gene expression in the post-transcriptional phase by precluding protein translation or supporting RNA (mRNA) degradation [31].

MicroRNAs (miRNAs) were shown to modulate gene expression and were altered in the aortic valve leaflets in patients with aortic valve stenosis compared to aortic insufficiency occurring in the landmark paper from the University of California 10 years ago [5].The reduced levels of miRNA-26a, RNA-30b, and miRNA-195 that have been reported in stenotic valves were almost certainly responsible for its higher risk of developing valvular leaflet fusion due to accelerated calcium accumulation compared to regurgitant aortic valves without morphological fusion of valve leaflets. These miRNAs were involved in the biological processes that modulate calcification-related genes in vitro [5].

Several studies have recorded a substantially inferior level of mi-RNAs that were associated with the pivotal function of post-transcriptional modulators of gene expression in aortic valve stenosis. The expression of miRNA-141 is implicated as a regulator of the levels of bone morphogenetic protein 2 (BMP-2), whereby unrestrained activity led to calcification of the 
aortic valve mediated by a stimulation of osteogenesis. miRNA141 was markedly attenuated in patients with aortic stenosis associated with the bicuspid aorta valve [6]. Yanagawa et al proposed the new key role of miRNA-141 in the modulation of aortic valve calcification disorders, highlighting the strategic therapeutic target that emerged in the assessment of progressive calcification in stenotic aortic valve disease [6]. The peculiar morphologic features of the stenotic aortic valve may probably be explained by the inferior expression of miRNA$30 \mathrm{~b}$ which is a known repressor of bone morphogenetic protein 2-mediated osteogenesis.

Zhang et al demonstrated the role of miRNA-30b in reducing osteoblast differentiation activity induced by bone morphogenetic protein 2 . The latter was implicated in promoting calcific aortic valve disease. The expression of miRNA-30b was effective in reducing the risk of human aortic valve calcification and apoptosis through direct targeting of Runx2, Smad1, and caspase-3

(Figure 1) [7].

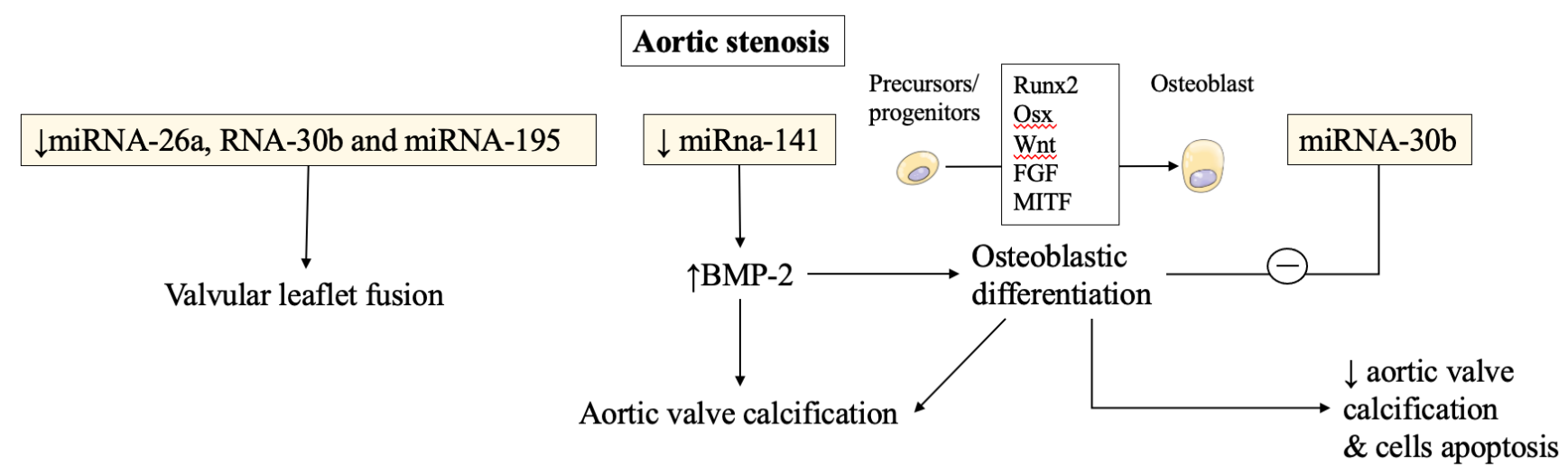

Figure 1: The role of miRNA in aortic stenosis severity and valve calcification. Reduced levels of miRNA-26a, miRNA-30b, and miRNA-195 contribute to further damage to the valve. The negative regulation exerted on osteoblastic differentiation by miRNA-30b favors a better prognosis. Abbreviations. BMP: bone morphogenetic protein. Runx2: RUNX Family Transcription Factor 2, OSX: osterix factor, FGF: Fibroblast growth factor, MITF: Microphthalmia-associated transcription factor

Song et al [8] investigated the transition of interstitial cells of the aortic valve and how myofibroblastic and osteoblast-like phenotypes play crucial roles in the progression of calcified aortic valve disease. The authors reported substantial differences in the levels of two miRNA 
classes: miR-486 and miR-204. The levels of miR-486 were increased, inducing the myofibroblastic transition with an upregulation of the expression of Runx2 and Osx, and synergized with the deficiency of miR-204, which lead to high cellular and valvular proosteogenic activity. This study demonstrated the existence of a sophisticated modulation of the epigenetic mechanism that supported pro-osteogenic valve activity, paving the way for the therapeutic potential for the prevention of the progression of calcified aortic valve disease.

Scientific evidence supports the differential expression of miRNAs in the bicuspid aortic valve, with an evident calcific-degenerative focus that differentiates the bicuspid morphology from the differential modulation of the tricuspid aortic valve [9].

\subsection{Diagnostic and prognostic relevance of mi-RNAs in mitral valve diseases}

In recent years, microRNAs have represented an emerging class of widely laboured circulating biomarkers in various pathological states including degenerative mitral valve disease [10-12].

Regarding MVP, we note only a small number of circulating microRNAs have been studied in degenerative disorders of the mitral valve, with the findings limited to the experimental animal models. Hulanicka et al [13] evaluated plasma for miRNAs as potential biomarkers of chronic myxomatous mitral valve disease (MMVD) in Dachshunds. The authors focused the study on the expression of 9 miRNAs already discovered and that were involved in cardiovascular pathologies. The plasma levels of two out of nine miRNAs were significantly downregulated with the use of real-time PCR method, so as to record clear involvement of them in dogs developing endocardiosis.

According to the American College of Veterinary Internal Medicine (ACVIM), the authors compared the plasma levels of miRNAs in three groups of dogs. They recorded that miR-30b expression differed between dogs of the ACVIM group in stage B (asymptomatic $n=8$ ) and those that were included in the unaffected stage A group (control $\mathrm{N}=8$ ). The expression of mi- 
133b differed in the ACVIM stage C group, in which mild to moderate heart failure occurred, compared to that of stage A group of dogs. 5 miRNAs (miR-125, miR-126, miR-21, miR-29b, and miR-30b) showed a downregulation trend only in the ACVIM stage C group recording nonsignificance for the expression of these classes of miRNA. Regarding the levels of miR-423, an equivalence was noted between healthy and sick dogs. The expression of miR-208a and 208b was not detected. The plasma level of miR-30b could be correlated as a potential biomarker of ACVIM stage B heart failure in Dachshunds who developed endocardiosis while miR-133b expression could be correlated as a potential biomarker of ACVIM stage C. It should be noted that the lack of expression or notable change in expression in 7 miRNAs which were potential biomarkers for the development of heart disease in humans highlight the lack of transferability from animal models to clinical applicability.

A second study [14] reported the miRNA expression profile in dogs suffering from MMVD (myxomatous mitral valve disease). Li et al quantified 277 miRNAs using RT-qPCR and comparing three groups of 6 dogs. The first group enrolled asymptomatic animals with no disease (ACVIM stage A control group). The second group included dogs exhibiting MMVD with mild to moderate enlargement of the heart chambers (ACVIM Stage B1 / B2). The third group included animals with MMVD and congestive heart failure (ACVIM Phase C / D). For eleven miRNAs, the study results showed a different expression with a False Discovery Rate $<0.05$. Dogs enrolled in group B who had stage B1 / B2 disease or those included in group C who had stage C / D disease recorded four upregulated miRNAs. These two groups included three cfa-let-7 / cfa-miR-98 family members with upregulation, while seven others were downregulated when compared to the stage A control group. The evidence suggested significant differences in the expression of six of the 11 miRNAs when comparing animals belonging to stage $\mathrm{C} / \mathrm{D}$ and those that were included in stage B1 / B2. In addition, the changes in miRNA expression were greater with the increasing severity of MMVD. The significance of this study 
relates to the fact that these miRNAs can be candidates biomarkers, providing further insights into specific genetic regulation pathways in MMVD that developed in dogs (Table 1) [14].

\begin{tabular}{|c|c|c|c|c|}
\hline \begin{tabular}{l}
\multicolumn{3}{l}{ Study groups } \\
Hulanicka et \\
al[13], Li et \\
al[14]
\end{tabular} & $\begin{array}{l}\text { miR-30b, } \\
\text { miR-29b }\end{array}$ & $\begin{array}{l}\text { miR-133b, miR- } \\
\text { 21, miR-126, } \\
\text { miR-423, miR- } \\
\text { 125, miR-208a, } \\
\text { miR-208b }\end{array}$ & $\begin{array}{l}\text { cfa-miR- } \\
302 d \text {, cfa-miR- } \\
\text { 380, cfa-miR- } \\
874 \text {, cfa-miR- } \\
582 \text {, cfa-miR- } \\
\text { 490, cfa-miR- } \\
\text { 329b, and cfa- } \\
\text { miR-487b }\end{array}$ & $\begin{array}{l}\text { cfa-miR- } \\
\text { 103, cfa- } \\
\text { miR- } \\
98 \text {, cfa-let- } \\
7 b \text {, and cfa- } \\
\text { let-7c }\end{array}$ \\
\hline $\begin{array}{l}\text { ACVIM stage } \\
\text { B HF [13] }\end{array}$ & downregulated & normal & not tested & not tested \\
\hline $\begin{array}{l}\text { ACVIM stage } \\
\text { C HF [13] }\end{array}$ & downregulated & downregulated & not tested & not tested \\
\hline $\begin{array}{l}\text { Group B (stage } \\
\text { B1, B2) [14] }\end{array}$ & not tested & not tested & downregulated & upregulated \\
\hline $\begin{array}{l}\text { Group C (stage } \\
C, D)[14]\end{array}$ & not tested & not tested & downregulated & upregulated \\
\hline
\end{tabular}

Table 1: The main results from preclinical studies testing miRNAs are tabulated. Stages B and

C from Hulanicka et al [13] respectively stand for asymptomatic and mild/moderate heart failure. group B and C from Li et al [14] represent myxomatous mitral valve disease (MMVD) stages B1 and B2 for group B, stages C and D for group C. Abbreviations: ACVIM; American College of Veterinary Internal Medicine, mi-R: micro-RNA.

The major concern with the use of animal models to evaluate the expression of miRNA is the increased risk of discrepancy with human pathoanatomic conditions. Bulent et al [15] worked around this problem by investigating the expression profile of circulating miRNAs in the development of mitral chordae tendineae rupture in humans. 22 miRNAs were studied in 
patients who developed mitral regurgitation due to progressive degeneration of the connective structure of the chordae tendineae leading to rupture. Evidence has suggested that the downregulation of various miRNA classes in patients with mitral valve degenerative disease led to rupture of chordae tendineae. Using bioinformatics analysis, the authors indicated the following target genes involved in MCTR (MMPs, TIMP-2, TGFBR2, VEGFA, PIK3R2, NRAS, PPP3CA, PPP3R1, PTGS 2) which were regulated by 13 miRNAs [15].

Songia et al [32] performed the first study using human plasma from patients with degenerative mitral valve prolapse and noted a strong correlation between several circulating miRNAs and mitral valves with myxomatous prolapse. Some of the tested miRNAs were also overlapping with those from Bulent et al [15] and a similarity emerged: lower levels of miRNA 223-3p was found in both patients suffering from MVP and patients who developed MCTR (Table 2).

\begin{tabular}{|l|l|l|l|l|l|l|l|l|l|}
\hline $\begin{array}{l}\text { Cardiovascular } \\
\text { diseases }\end{array}$ & $\begin{array}{l}\text { 140- } \\
\mathbf{3 p}\end{array}$ & $\begin{array}{l}\mathbf{1 5 0}- \\
\mathbf{5 p}\end{array}$ & $\begin{array}{l}\mathbf{2 1 0}- \\
\mathbf{3 p}\end{array}$ & $\mathbf{4 5 1 a}$ & $\begin{array}{l}\mathbf{4 8 7 a}- \\
\mathbf{3 p}\end{array}$ & $\begin{array}{l}\mathbf{2 2 3}- \\
\mathbf{3 p}\end{array}$ & $\begin{array}{l}\mathbf{3 2 3 a}- \\
\mathbf{3 p}\end{array}$ & $\begin{array}{l}\mathbf{3 6 1 -} \\
\mathbf{5 p}\end{array}$ & $\begin{array}{l}\mathbf{3 4 0}- \\
\mathbf{5 p}\end{array}$ \\
\hline $\begin{array}{l}\text { MVP versus } \\
\text { controls }\end{array}$ & $\uparrow$ & $\uparrow$ & $\uparrow$ & $\uparrow$ & $\uparrow$ & $\downarrow$ & $\downarrow$ & $\downarrow$ & $\downarrow$ \\
\hline $\begin{array}{l}\text { MCTR } \\
\text { versus } \\
\text { controls }\end{array}$ & $/$ & $\downarrow$ & $/$ & $/$ & $/$ & $\downarrow$ & $/$ & $/$ & $/$ \\
\hline
\end{tabular}

Table 2: Concordant results from Bulent et al[15]and Songia et al[32]. Patients affected by MTCR were found to have lower levels of miRNA 150-5p with respect to controls while miRNA-223-3p was found to be lower than controls, compared to patients affected by MVP. (Slashes indicate that some results of miRNA testing on MCTR were not available.) Abbreviations. MVP: mitral valve prolapse, MCTR: mitral chordae tendineae rupture. 
The authors working on circulating biomarkers have provided valuable information on the etiology of degeneration and prolapse of MV alongside the possibility of stratifying patients affected by the disease.

Deroyer et al [33] investigated the role of apolipoprotein-A1 in fibroelastic disorders of MV revealing that the biomarker was indicated as an independent predictor of MR gravity.

In another study, Tan et al [12] performed an analysis using proteomic evaluation on two pooled plasma samples from 24 individuals affected by mitral valve prolapse and MR compared to 24 individuals with no MV prolapse and failure. All enrolled patients received combinatorial peptide ligand library (CPLL) beads prior to iTRAQ labeling and ESI-MS/MS. Authors noted a decrease in circulating levels of plasma haptoglobin, basic platelet protein, and complement component $\mathrm{C} 4 \mathrm{~b}$ in patients who developed MR due to fibroelastic deficiency compared to those without degenerative MV disorders. The results were confirmed with the ELISA test which was performed in all 48 patients enrolled in the study and matched 48 additional individual ELISA tests.

Unlike the studies cited above, the results reported in the analysis by Songia et al were supported by solid statistical evidence, underlined by a marked change in plasma level of the miRNAs (miRNA-150-5p, miRNA-451a, and miRNA-487a-3p) studied using AUROC curves. The keynote of the study was the fact that the authors assessed a cell-type enrichment analysis, based on validated miRNAs, revealing the existence of specific cell populations morphogenetically linked to different cardiovascular tissues, including the morphogenetic specificity of the mitral valve tissue. This suggested a link between ERBB and JAK-STAT signaling pathways as potentially relevant to understanding the recently discovered mechanisms involved in the evolution of mitral valve prolapse.

Among other things, the study of Songia et al confirmed the existence of well-characterized signaling pathways involved in cell migration and proliferation of endothelial cells 
$[11,12,34,35]$ as well as in the deregulation of homeostasis of the extracellular matrix [36-38]. In particular, the authors demonstrated that patients who develop degenerative disease of the mitral valve, either in the fibroelastic or myxomatous form, recorded a different expression of miRNA-150-5p leading to several pathological processes including fibrosis and neoplastic proliferation [39-41].

Although the report [32] claimed that specific circulating biomarkers could be interpreted as molecular signatures, the study has some critical points. The study lacks numerically validated data in the different miRNA expressions between patients who had fibroelastic degenerative disease of MV and those who instead presented a myxomatous degeneration typically related to Barlow syndrome. In addition, the cohort of patients studied concerns those with degenerative prolapse of the MV with severe MR and eligible for surgical treatment. In fact, the study did not report any evaluation of the plasma levels of miRNAs capable of identifying a larger cohort of individuals with a prolapse of the MV coexisting with a mild or moderate mitral insufficiency.

However, given the reported evidence, the future direction postulates that miRNAs identified in plasma could be used in the near future and is an inexpensive screening tool for patients with progressive degenerative mitral valve disease and severe mitral regurgitation.

\section{Pathophysiology of valvular calcification pathways, from preclinical models to clinical} perspectives

\subsection{Complex interplays between mi-RNAs and intracellular osteogenic signals}

Calcium phosphate crystals are responsible for abnormal accumulation in either native or prosthetic valves, leading to valvular calcification (VC), loss of elasticity, and ischemic conditions [42]. Intimal and medial layers of major vessels can display calcifications, the former being associated with atherosclerotic phenotypes, the latter with common cardiovascular risk 
factors including diabetes and osteoporosis. Some authors propose vascular smooth muscle cells (VSMCs) to begin the process by undergoing phenotypical changes to osteoblastic nature and losing contractile markers such as smooth muscle 22 alpha (SM22 $\alpha$ ) and alpha-smooth muscle actin ( $\alpha$-SMA) [43].

Several coding genes have been studied and linked to the specific development of calcific valves. Osteopontin (OPN), osteocalcin (OC), bone morphogenetic proteins (BMPs), alkaline phosphatase (Alp), and transcription factor Runx2 were demonstrated to be upregulated in calcific processes [42]. Other described signaling pathways include exosomes cross-talk among the three layers of the vascular wall and Wnt/Beta-catenin, advanced glycation end products (AGEs), and osteoprotegerin/ receptor activator of nuclear factor-kB and its ligand (OPG/RANK/RANKL) interacting between either the intima and media layers or the media and adventitia layers $[44,45]$.

Pro-inflammatory activity has also been related to VC. Tumor necrosis factor-alpha (TNFa), interleukins including IL-1B and IL-6, tumor growth factor-beta 1 (TGFB1), and other cytokines mediate vascular smooth muscle cells transition into osteoblast-like cells [46]. The phenomenon is known to be enhanced by reactive oxygen species (ROS) production and determined by the discovery of cytokines and factors expression in the aortic tissue. A Canadian preclinical study by Agharazii et al [46] demonstrated valvular calcification processes developing from chronic kidney disease, to be increased in rats by cytokines. Interleukin-1 $\beta$, interleukin-6, and tumor necrosis factor were overexpressed in aortic tissues. Also, nicotinamide adenine dinucleotide phosphate (NADPH) oxidase expression was increased while antioxidant enzymes (SOD1, SOD2, Gpx1, and Prdx1) demonstrated lower levels than normal [46].

MicroRNAs, small non-coding RNAs, and long non-coding RNAs are part of the broader group of non-coding RNAs. MicroRNAs, with the exception of miR-29, have been categorized into 
either activating or promoting valvular calcification. Some authors claim miR-29a/b repression is a pivotal factor in calcification generation. A preclinical study by Du and colleagues [47] revealed how increased expression of ADAMTS-7 (a disintegrin and metalloproteinase with thrombospondin motifs-7), markedly upregulated in calcifying rat vascular smooth muscle cells, is linked to miR-29 inhibition. Calcification inhibitors miRNAs, which roles were revealed by decreased expression in calcific tissues, have been described by in vitro and in vivo studies, in both animals and humans. MiR-30b, 30c were found to directly inhibit Runx2 factors, such as miR-133a, miR-204, and miR-205 [48-51].

Recently, Lin and colleagues [52] demonstrated miR-34c/5p to be downregulated in calcific tissues (in vitro high glucose-induced human aorta VSMCs) and inhibiting BMF as the primary target. In fact, miR-34c from the miR-34 family is reported to participate in osteoblast differentiation $[53,54]$. It targets SATB2, a nuclear matrix protein that inhibits the expression of HOXA2, in turn negatively regulating Runx2 and increases the activity of Runx2 and activator transcription factor 4 (ATF4). Runx2 and ATF4 are sophisticated regulators of osteoblastic differentiation, from osteochondral progenitors. Osterix is another important involved factor [55]. Investigators also claim miR-34c regulates Osteocalcin and other genes whose expression is controlled by Runx2 and SATB2 or ATF4 and SATB2 [53].

\subsection{Over and underexpression of miRNAs from in vivo animal experimentations}

Recently, investigators have provided proof of upregulated levels of miRNAs in calcific vessels. An in vitro demonstration of human and murine aortic tissue and, specifically, of smooth muscle cells expressing miR-29b at increased levels comes from a Japanese investigation [56] and a Spanish preclinical study [57].

Panizo et al [57] induced vessels calcification in rats by using the common experimental method of feeding them a high phosphate diet. They found low levels of miR-133b and miR-211 and high levels of miR-29b. The former correlated with overexpression of osteogenic RUNX2, the 
previously described factor, while the latter with lower expression of inhibitors of osteoblastic differentiation. The reliability of the study is conferred by in-vitro affirmation of the results: authors analyzed miR-29b, miR-133b, and miR-211 to demonstrate how they regulated the calcification process [57]. MiR-29-mediated elastin down-regulation also promotes osteoblastic differentiation [56]. Calcium deposition in human VSMCs favoured by phosphorus ( $\mathrm{Ph}$ ) was evaluated by Sudo and colleagues [56] to determine the impact of miR-29. Real-time quantitative PCR (RT-qPCR) analysis on Pi-induced calcific VSMCs was performed and showed decreased levels of elastin with consequent osteoblast-related genes expression. Of note, miR-29 was found to elicit elastin suppression, thereby closing the circle.

To further evaluate the role of mi-RNAs in valvular calcification, exosomes from VSMCs have been evaluated by several authors through RT-qPCR. Interestingly, preclinical studies show differences in the expression of hundreds of mi-RNAs when comparing mice calcific models versus the normal population $[58,59]$.

Pan et al [58] established a cellular calcification model using the mouse line MOVAS-1. To search for calcification, Alizarin Red staining was performed and differential mi-RNAs profiles were sequenced. Results showed 987 mi-RNAs to be upregulated in the cellular calcification model and 92 to be down-regulated, even though not all of them were showing significant pvalues of comparison between the two populations' expression. 
Selected significant results are tabulated in Table 3.

\begin{tabular}{|c|c|c|}
\hline Gene ID for each mi-RNA & Calcific model Expression & P-value \\
\hline mmu-miR-682 & Upregulated & $8,7^{-290}$ \\
\hline mmu-miR-29b-1-5p & Upregulated & $7,55^{-53}$ \\
\hline mmu-miR-133b-3p & Upregulated & $1,8^{-66}$ \\
\hline mmu-miR-211-5p & Upregulated & $1,5^{-22}$ \\
\hline mmu-miR-34c-3p & Upregulated & Non-significant \\
\hline mmu-miR-204-3p & Upregulated & $6,34^{-64}$ \\
\hline mmu-miR-205-3p & Upregulated & $2,2^{-137}$ \\
\hline mmu-miR-155-5p & Downregulated & $7,1^{-22}$ \\
\hline mmu-miR-93-5p & Downregulated & $4,5^{-141}$ \\
\hline mmu-miR-24-3p & Downregulated & $2,9^{-283}$ \\
\hline mmu-miR-146a-5p & Downregulated & $5,5^{-187}$ \\
\hline mmu-miR-191-5p & Downregulated & $8,1^{-166}$ \\
\hline
\end{tabular}

Table 3. Results of selected miRNAs are tabulated according to their level of expression in calcific tissue. Statistical data were taken from Supplementary data, Pan et al [57]. MiR-29b, miR-133b, and miR-211-5p show increased levels of expression in calcific VSMCs. Similar results were obtained by other investigators and discussed above. 


\section{Altered miRNAs expression in congenital valve disorders and cardiogenetic processes}

Congenital heart diseases (CHD) comprise a large group of functional and structural disorders, namely atrial septal defects (ASD), ventricular septal defects (VSD), pulmonary valve atresia (PVA), coarctation of the aorta (CoA), tricuspid atresia (TA), tetralogy of Fallot (TOF) and several others [60-62]. Mi-RNAs play a pivotal role in heart development. The process of cardiac tissue formation and expression requires precise regulation and single mi-RNAs studies have been addressed in past decades. MiR-1 and miR-133 are transcribed in a tissue-specific manner during development [63]. MiR-1 targets HDAC4, histone deacetylase 4 which is a repressor for muscle gene expression, thereby stimulating myogenesis. MiR-133 inhibits serum response factor (SRF) and promotes the differentiating process [63].

Several other preclinical studies, conducted on zebrafish ventricles, denoted the role of miR133 to diminish cardiac regenerating processes [64]. Following resection of zebrafish ventricular apex, a reduced expression of miR-133, coupled with an increased regenerative potential, has led to this concept [64].

Cardiogenesis is also suppressed by the miR-15 family, which, specifically inhibited, has shown to promote myocyte proliferation after myocardial infarction [65]. On the contrary, miR-199 and miR-590 have been found to promote the re-entry of cardiomyocytes in the cell cycle. An interesting therapeutical strategy, supported by preclinical mice studies, would be to inject these molecules into the border zones of infarcted hearts. Positive results and stimulation of cardiomyocytes proliferation have been demonstrated [66,67].

Several mi-RNAs also regulate the signals of insulin-growth factor 1 (IGF-1) in skeletal muscle, contribute to muscle development or atrophy [68]. Several other studies have noted their regenerative role by observing common cardiovascular pathologies and the subsequent structural remodeling [69]. Long non-coding RNAs are implied in hypertension-related vascular remodeling, post-ischemic recovery, and myocardial hypertrophy (Table 4) [69]. 


\begin{tabular}{|l|c|}
\hline Long non-coding RNAs and factors & Mechanism of involvement \\
\hline $\begin{array}{l}\text { lncRNA TUG1, AK098656, TRPV1, GAS5, } \\
\text { Giver, and Lnc-Ang362 }\end{array}$ & hypertension-related vascular remodeling \\
\hline $\begin{array}{l}\text { H19, TUG1, UCA1, MEG3, APPAT, and } \\
\text { lincRNA-p21 }\end{array}$ & atherosclerosis \\
\hline HIF1A-AS1 and Lnc-HLTF-5 & \multicolumn{1}{|c|}{ aortic aneurysm } \\
\hline $\begin{array}{l}\text { Neat1, AK139328, APF, CAIF, AK088388, } \\
\text { CARL, MALAT1, HOTAIR, XIST, and } \\
\text { NRF }\end{array}$ & postischemia myocardial remodeling \\
\hline $\begin{array}{l}\text { Mhrt, Chast, CHRF, ROR, H19, Plscr4, and } \\
\text { MIAT }\end{array}$ & $\begin{array}{c}\text { myocardial hypertrophy } \\
\text { MALAT1, wisper, MEG3, and H19 }\end{array}$ \\
\hline
\end{tabular}

Table 4. LncRNAs (long non-coding RNAs) are tabulated for the mechanism they are mostly involved in. Abbreviations. TUG1: taurine upregulated 1; TRPV1: transient receptor potential vanilloid type 1; GAS5: growth block specificity 5; Giver: growth factor-and proinflammatory cytokine-induced vascular cell-expressed lncRNA; UCA1: urothelial carcinoma-associated; MEG3: maternally expressed gene 3; APPAT: atherosclerotic plaque pathogenesis associated transcript; lincRNA-p21: long intergenic noncoding RNA-p21; Neat1: nuclear paraspeckle assembly transcript 1; HIF1A-AS1: HIF1 alpha-antisense RNA1; ACP5: acid phosphatase 5; SM: smooth muscle. Neat1: nuclear-enriched abundant transcript1; APF: autophagy promoting factor; CAIF: cardiac autophagy inhibitory factor; CARL: cardiac apoptosis-related lncRNA; MALAT1:metastasis-associated lung adenocarcinoma transcript 1; HOTAIR:HOX antisense intergenic RNA; UCA1:urothelial carcinoma-associated; XIST: X-inactive specific transcript; Mhrt: myosin heavy chain associated RNA transcripts; Chast: cardiac hypertrophy-associated transcript; Plekhm1:pleckstrin homology domain-containing protein family $\mathrm{M}$ member 1; CHRF: cardiac hypertrophy-related factor; MIAT: myocardial infarction-associated transcript. 
Specific miRNAs are also differentially expressed in bicuspid aortic valve (BAV), the most common congenital heart disease. Aortic valve endothelial cells on the ventricular side are frequently exposed to high shear forces while on the aortic side turbulent blood flow and high levels of antioxidant enzymes are present [70].

Conversely, on the ventricular side, factors inhibiting calcification are more abundant $[70,71]$. Sabatino and colleagues [9] performed a bioinformatic analysis in order to identify the most commonly regulated miRNAs in normal and stenotic bicuspid aortic valves and compared results with normal and stenotic tricuspid valves with respect to calcium metabolism, blood coagulation, phosphate metabolism, and inflammatory pathways. MiR-133 can be used for guiding the therapeutic management of aortic stenosis, due to its potential role in predicting left ventricular hypertrophy [72-74]. Authors found that its levels were differentially expressed in bicuspid versus tricuspid aortic valve and were also correlated with the degree of stenosis, as previously discussed. Investigators claim it will be used as a biomarker as it reflects the degree of myocardial fibrosis [9].

The key factor involved in calcium metabolism and inflammatory pathways was found to be Epidermal growth factor receptor (EGFR). Several miRNAs, also associated with calcification, were associated with stenotic tricuspid aortic valves (TAVs) and BAVs, namely miR-100, $-130 a,-181 a / 181 b,-199 a-5 p,-199 a-3 p$, and -214 which have been investigated by other authors to display higher expression levels in VECs of the fibrosa on the aortic side, compared to the ventricular side [75].

MiR-181 is another important mi-RNA. Aortic valve endothelial cells were associated with its increased expression but decreased levels of targets, including SIRT1 and GATA6 that negatively affect vascular SMCs elastin production [76]. Several other studies confirmed that its inhibition increases the expression of elastin and collagen while its stimulation, through direct administration, inhibits atherosclerotic lesion formation [77]. 


\section{Novel therapeutical strategies: mi-RNAs targeting to suppress or activate them}

\subsection{Results from in-vivo and in-vitro testing for aortic valvular stenosis}

Regulating miRNAs expression is an attractive therapeutical challenge. Valvular calcification is currently not a direct target for pharmacological action. Endothelin receptor antagonists have emerged as possible molecules of interest in preclinical studies [78,79]. Chronic kidney diseaseinduced valvular calcification was demonstrated to be slowed by administration of endothelin type A (ETA) receptor atransentan $(10 \mathrm{mg} / \mathrm{kg} /$ day) which reduced SMC differentiation, calcification, and stiffness [78].

Concerning statin treatment, several studies reported increased rates of calcification [80]. Possible strategies for mi-RNAs overexpression include mi-RNA mimics, mi-RNA expression vectors, and small molecules [59,81]. Instead, negatively regulating mi-RNAs seems to encompass different strategies. Antisense oligonucleotides including locked nucleic acid (LNA)-modified anti-miR, or miRNA sponge vectors can be used to specifically binding to miRNAs [59]. Toshima and colleagues [82] demonstrated miR-34a as a potential therapeutic target. Its inhibition in human aortic tissue exhibiting either calcific aortic valve stenosis (CAVS) or aortic regurgitation (AR) attenuated calcification signals in porcine aortic valve interstitial cells (AVICs) compared with miR-control. After performing RNA pull-down assays, miR-34a was demonstrated to directly target Notch1 by binding to Notch1 mRNA 3' untranslated region [82]. Also, miR-34a inhibitor suppressed calcium deposition of aortic valves and cardiac hypertrophy, both mechanisms involved in decreased Runx2 and increased Notch1 expressions [82].

Another possible strategy recently proposed, involves melatonin administration. In vitro studies confirmed melatonin reduces the level of CircRIC3, a circular RNA with procalcific effects. It acts as a miR-204-5p sponge to stimulate and increase expression levels of the procalcification gene dipeptidyl peptidase-4 (DPP4). 
A preclinical in vivo study [83] involving high cholesterol diet (HCD)-treated $\mathrm{ApoE}^{-/-}$mice with aortic valve calcification demonstrated that the intragastric administration of melatonin for 24 weeks improved aortic valvular parameters. It reduced thickness and calcium deposition in the leaflets and ameliorated echocardiographic markers, namely transvalvular peak jet velocity and aortic valve area [83]. At the molecular level, it decreased Runx2, osteocalcin, and osterix factors which are involved in osteogenic differentiation, as we discussed above (Figure 2).

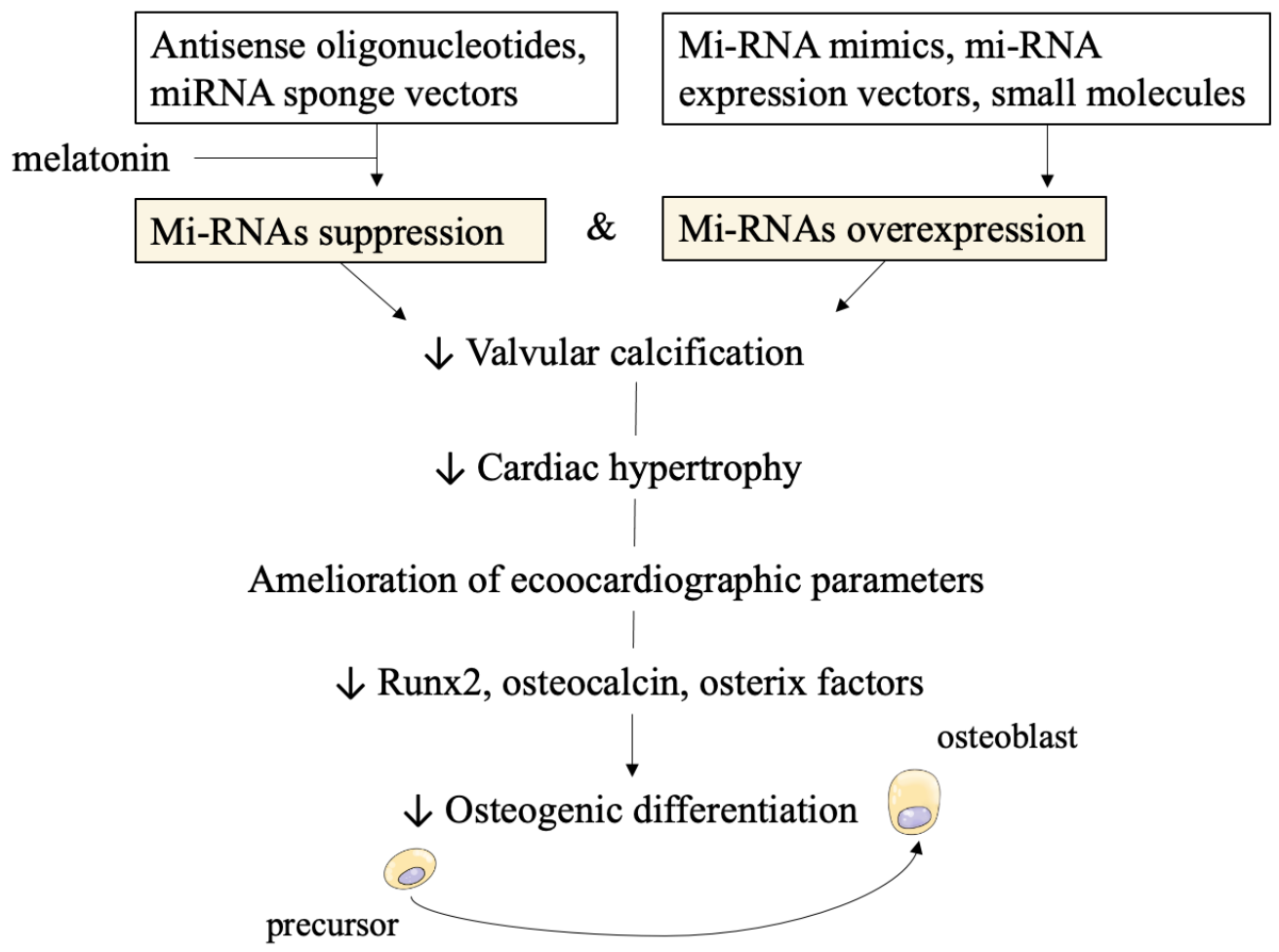

Figure 2. Possible therapeutic strategies and in vitro/in vivo effects of mi-RNAs targeting. Technological approaches of suppressing and overexpressing mi-RNAs are displayed at the top of the figure. The subsequent reduction in calcification clinical parameters and molecular pathways is achieved.

The authors also demonstrated melatonin caused in vitro suppression of calcification in human valvular interstitial cells (hIVICs) [83]. 


\subsection{Technical concerns on stability and efficacy of mi-RNAs as therapeutical targets}

The primary concerns in utilizing mi-RNAs as therapeutic targets, either to positively or to negatively affect them, arise from the need of achieving stability and resistance to degradation enzymes. We named expression vectors, antisense nucleotides (ASOs), small molecules and miR-mimics as novel approaches under current experimentation. Expression vectors are also defined mi-RNAs sponges and constitute artificial binding sites for mi-RNAs to reduce their effect on mRNAs $[84,85]$. Oligonucleotides also bind mi-RNAs but are regarded as anti-miR for their sequence complementarity. With this strategy, they relieve mRNA targets from degradation or transcriptional blockage. Small molecules serve as translational regulators instead but specific targets have not been revealed yet.

A possible strategy to improve stability is modification with 2-O-methyl (2 -OMe) [86]. This can be then further stabilized with sulfur atoms in place of non-bridging oxygen atoms in the phosphate backbone. Serum nucleases, deputed to degradation of mi-RNAs, would find difficult to cleave phosphorothioate bonds, given that they normally cleave phosphate bond [86, 87]. The adding of a $3^{\prime}$ cholesterol tail is another approach to ameliorate stability and efficacy. To decrease nuclease degradation, modifications including 2-O-methoxyethyl (2 -MOE), 2 fluoro (2-F), and locked nucleic acid (LNA) have also been tested [84]. In particular, 2'-Fmodifications yield resistant nucleotides only in combination with phosphorothioate modifications and proved to be the most effective one [88].

\subsection{Disadvantages in pharmacokinetics and proposed mechanisms for delivery vehicles}

In vitro studies conducted on oligonucleotides had limited pharmacological effects due to unfavourable kinetic characteristics, notably poor tissue distribution and fast excretion. Thus, appropriate delivery systems have been developed, functioning as carriers for in vivo molecular directing [84]. 
A good delivery system should achieve the following features: evading the immune system response, avoiding nuclear degradation, directed to target cells, and releasing the content for incorporation into RNA processing machinery [89-92]. The main combination strategies include polymers, lipids, conjugation, antibodies, nanoparticles, and microbubbles [84]. In particular, nanoparticles can deliver anti-miRNAs and small molecules with a greater degree of multifunctionality [93]. The advantages of nanoparticles include large surface-to-volume ratios, hence, controlling their surface properties is crucial [94]. Surface charges also appear fundamental: macrophage scavenging is increased when the charge increases in number (either positive or negative) $[93,95,96]$. So, minimizing interactions to non-target sites via, as an instance, steric stabilization, would prevent nanoparticles from directing the molecules to undesired locations, and evading the immune system.

Other emerging technologies to improve kinetic parameters are nanoscale drug delivery systems using liposomes [97]. Lower systemic toxicity has also been proved, especially in achieving high efficacies for anticancer therapies [98-100]. Microbubbles, instead, have been used in combination with ultrasound to deliver anti-mi-RNAs after ischemia towards myocardiocytes of mice models. Molecular structure of microbubbles include mixing of 1,2distearoyl-sn-glycero-3-phosphocholine, 1,2-stearoyl-3-trimethylammonnium-propane and polyoxyethylene-40-stearate in $\mathrm{H}_{2} \mathrm{O}$, glycerol, and propylene glycol, in the presence of perfluorobutane gas [84, 101-104].

Local mi-RNA delivery results have been published and discussed in an Israeli study for metastatic breast cancer prevention by miR-96 and miR-182 treatment [105]. In vivo, local targeting was achieved by coating breast tumour cells with adhesive hydrogel scaffold covered in nanoparticles carrying the miRNAs of interest [105]. Nanoparticle stability achieved with hydrogel was also described for drug delivery in several other studies [106-108]. 


\section{Conclusions: clinical relevance of preclinical studies and future directions}

An Italian group discussed the potential use of mi-RNAs for mitral valve diseases [109]. Matrix metalloproteinase (MMP) with their genetic variants and mi-RNAs appear as predictive diagnostic and prognostic biomarkers but, most promisingly, as potential targets for personalized treatments [109] (figure 3).

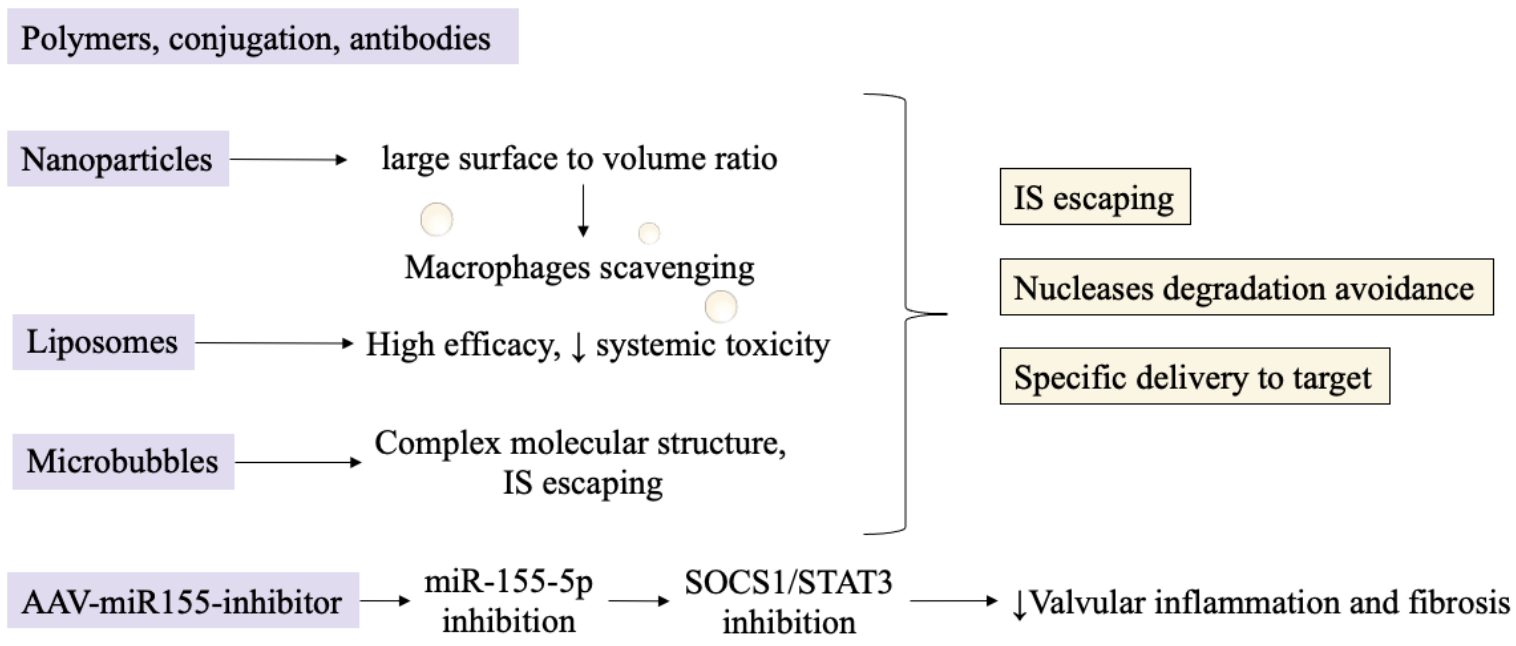

Figure 3. Novel methods and delivery systems for targeting mi-RNAs are depicted with their respective advantages. IS escaping, nucleases degradation, and specific delivery are features to be achieved by an optimal delivery system. The pathophysiological conclusion from a study regarding AAV-miR155-inhibitor, an adenoviral-based mi-RNA inhibitor, discussed below in the text, is also reported. Abbreviations. IS: immune system, AAV: adeno-associated virus, SOCS1: suppressor of cytokine signaling 1, STAT3: signal transducer and activator of transcription 3.

At present, no clinical data on therapeutic approaches targeting mi-RNAs are available. A preclinical study [110] investigated the use of recombinant adeno-associated virus (AAV-miR155-inhibitor) to inhibit the expression of miR-155-5p for valvular damage caused by rheumatic heart disease (RHD) in rat models. The different method, comprising an adenoviral delivery, enabled promising results to be demonstrated. Valvular expression of 
miR-155-5p was increased while SOCS1/STAT3 signaling was activated in the study rat population. The authors utilized dual-luciferase assays to display targeting by miR-155-5p of S1PR1 and SOCS1.

Inhibition of valvular miR-155-5p prevented activation of the SOCS1/STAT3 signal pathway and this resulted in suppression of valvular inflammation, detected as decreased tissue levels of Il-6 and Il-17 and fibrosis, both in valves and rats serum.

In conclusion, despite the current limitations of mi-RNAs molecular interactions and pathophysiological mechanisms to the preclinical scenario (both in vitro and in vivo), realising the possible therapeutic effects is fast becoming possible. We auspicate that in the coming years, further emphasis will be placed on these fascinating molecular approaches.

Funding: This research received no external funding.

Conflicts of Interest: The authors declare no conflict of interest

\section{Abbreviations}

MVP: mitral valve prolapse

siRNAs: short interfering RNAs

MiRNA: micro-RNA

BMP-2: Bone morphogenetic protein 2

Runx2: RUNX Family Transcription Factor 2

OSX: osterix factor

FGF: Fibroblast growth factor

MITF: Microphthalmia-associated transcription factor

ACVIM: American College of Veterinary Internal Medicine

MMVD: myxomatous mitral valve disease

MTCR: mitral chordae tendineae rupture 
CPLL: combinatorial peptide ligand library

iTRAQ: Isobaric Tags for Relative and Absolute Quantitation

ESI-MS/MS: electrospray ionization mass spectrometry

MMPs: Matrix metalloproteinase

TIMP-2: Tissue inhibitor of metalloproteinases 2

TGFBR2: transforming growth factor beta receptor 2

VEGFA: vascular endothelial growth factor alpha

PIK3R2: phosphoinositide-3-kinase regulatory subunit 2

NRAS: neuroblastoma RAS

PPP3CA: Protein Phosphatase 3 Catalytic Subunit Alpha

PPP3R1: Protein Phosphatase 3 Regulatory Subunit B, Alpha

PTGS 2: Prostaglandin-Endoperoxide Synthase 2

AUROC: Area Under the Receiver Operating Characteristics

JAK-STAT: Janus kinase-signal transducer and activator of transcription

MV: mitral valve

MR: mitral regurgitation

VC: valvular calcification

VSMCs: vascular smooth muscle cells

SM22 $\alpha$ : smooth muscle 22 alpha

a-SMA: alpha-smooth muscle actin

OPN: Osteopontin

OC: osteocalcin

BMP: bone morphogenetic proteins

Ap: alkaline phosphatase

AGEs: advanced glycation end products 
OPG/RANK/RANKL: osteoprotegerin/ receptor activator of nuclear factor-kB and its ligand

TNF- $\alpha$ : Tumor necrosis factor-alpha

TGFB1: tumor growth factor-beta 1

ROS: reactive oxygen species

NADPH: nicotinamide adenine dinucleotide phosphate

SOD1: superoxide dismutase 1

SOD2: superoxide dismutase 2

Gpx1: Glutathione Peroxidase 1

Prdx 1: Peroxiredoxin 1

ADAMTS-7: a disintegrin and metalloproteinase with thrombospondin motifs-7

SATB2: Special AT-rich sequence-binding protein 2

ATF4: activator transcription factor 4

HOXA2: Homeobox A2

Ph: phosphorus

RT-qPCR: Real-time quantitative PCR

CHD: Congenital heart diseases

ASD: atrial septal defects

VSD: ventricular septal defects

PVA: pulmonary valve atresia

CoA: coarctation of the aorta

TA: tricuspid atresia

TOF: tetralogy of Fallot

HDAC4: histone deacetylase 4

SRF: serum response factor

IGF-1: insulin-growth factor 1 
TUG1: taurine upregulated 1

TRPV1: transient receptor potential vanilloid type 1

GAS5: growth block specificity 5

Giver: growth factor-and proinflammatory cytokine-induced vascular cell-expressed lncRNA

UCA1: urothelial carcinoma-associated

MEG3: maternally expressed gene 3

APPAT: atherosclerotic plaque pathogenesis associated transcript

lincRNA-p21: long intergenic noncoding RNA-p21

Neat1: nuclear paraspeckle assembly transcript 1

HIF1A-AS1: HIF1 alpha-antisense RNA1

ACP5: acid phosphatase 5

SM: smooth muscle

Neat1: nuclear-enriched abundant transcript1

APF: autophagy promoting factor

CAIF: cardiac autophagy inhibitory factor

CARL: cardiac apoptosis-related lncRNA

MALAT1: metastasis-associated lung adenocarcinoma transcript 1

HOTAIR: HOX antisense intergenic RNA

UCA1: urothelial carcinoma-associated

XIST: X-inactive specific transcript

Mhrt: myosin heavy chain associated RNA transcripts

Chast: cardiac hypertrophy-associated transcript

Plekhm1: pleckstrin homology domain-containing protein family M member 1

CHRF: cardiac hypertrophy-related factor;

MIAT: myocardial infarction-associated transcript. 
EGFR: Epidermal growth factor receptor

TAV: tricuspid aortic valve

BAV: bicuspid aortic valve

SIRT1: Sirtuin 1

GATA6: GATA Binding Protein 6

ETA: endothelin type A

LNA: locked nucleic acid

CAVS: calcific aortic valve stenosis

AR: aortic regurgitation

AVICS: aortic valve interstitial cells

CircRIC3: circular RNA

DPP4: dipeptidyl peptidase-4

HCD: high cholesterol diet

hIVICs: human valvular interstitial cells

ASOs: antisense nucleotides

2-OMe: 2-O-methyl

IS: immune system

AAV: adeno-associated virus

SOCS1: suppressor of cytokine signaling 1

STAT3: signal transducer and activator of transcription 3.

AAV: adeno-associated virus

RHD: rheumatic heart disease

S1PR1: Sphingosine-1-Phosphate Receptor 1 


\section{References}

1. Mayeux, R. Biomarkers: potential uses and limitations. NeuroRx 2004, 1, 182-188, doi :10.1602/neurorx.1.2.182.

2. Kumar D.; Narang, R.; Sreenivas, V, et al. Circulatory miR-133b and miR-21 as 395 Novel Biomarkers in Early Prediction and Diagnosis of Coronary Artery Disease. Genes (Basel) 2020, 11, 396 doi:10.3390/genes11020164. 397

3. Ikeda, S.; Kong, S.W.; Lu, J.; Bisping, E. ; et al. Altered microRNAs 398 expression in human heart disease. Physiol Genomics 2007, 31, 367-373, doi :10.1152/physiolgenomics.00144.2007. 399

4. Guo, X.; Chen, Y.; Lu, Y. ; Li, P. ; Yu, H. ; Diao, F.R. ; Tang, W.D. ; Hou, P. ; Zhao, X.X. ; Shi, C.Y. High level of circulating 400 microRNA-142 is associated with acute myocardial infarction and reduced survival. Ir J Med Sci 2020, 189, 933-937, 401 doi $: 10.1007 / \mathrm{s} 11845-020-02196-5.402$

5. Nigam, V, Sievers H.H. ; Jensen, B.C. et al. Altered microRNAs in 403 bicuspid aortic valve: a comparison between stenotic and insufficient valves. J Heart Valve Dis 2010, $19,459-465.404$

6. Yanagawa, B. ; Lovren, F. ; Pan, Y. ; Garg, V. ; Quan, A. ; Tang, G. ; Singh, K.K. ; Shukla, P.C. ; Kalra, N.P. ; Peterson, M.D., et al. miRNA-141 is a novel regulator of BMP-2-mediated calcification in aortic stenosis. J Thorac Cardiovasc Surg 2012, 144, 256-406 262, doi : 10.1016/j.jtcvs.2011.10.097

7. Zhang M, Liu X, Zhang X, Song Z, Han L, He Y, Xu Z. MicroRNA-30b is a multifunctional regulator of aortic valve interstitial cells. J Thorac Cardiovasc Surg. 2014 Mar;147(3) :1073-1080.e2. doi : 10.1016/j.jtcvs.2013.05.011. Epub 2013 Aug 19. 
8. Song R, Fullerton DA, Ao L, Zhao KS, Reece TB, Cleveland JC Jr, Meng X. Altered MicroRNA Expression Is Responsible for the Pro-Osteogenic Phenotype of Interstitial Cells in Calcified Human Aortic Valves. J Am Heart Assoc. 2017 Apr 24 ;6(4) : e005364. doi : 10.1161/JAHA.116.005364.

9. Sabatino J, Wicik Z, De Rosa S, Eyileten C, Jakubik D, Spaccarotella C, Mongiardo A, Postula M, Indolfi C.Spaccarotella C, Mongiardo A, Postula M, Indolfi C MicroRNAs fingerprint of bicuspid aortic valve. J Mol Cell Cardiol. 2019 Sep; 134:98-106. doi: 10.1016/j.yjmcc.2019.07.001. Epub 2019 Jul 3.

10. Songia, P.; Branchetti, E.; Parolari, A.; Myasoedova, V.; Ferrari, G.; Alamanni, F.; Tremoli, E.; Poggio, P. Mitral valve endothelial cells secrete osteoprotegerin during endothelial mesenchymal transition. J Mol Cell Cardiol 2016, 98, 48-57, 386 doi: 10.1016/j.yjmcc.2016.06.061. 387

11. Songia, P.; Porro, B.; Chiesa, M.; Myasoedova, V.; Alamanni, F.; Tremoli, E.; Poggio, P. Identification of Patients Affected by Mitral Valve Prolapse with Severe Regurgitation: A Multivariable Regression Model. Oxid Med Cell Longev 2017, 2017, 389 6838921, doi:10.1155/2017/6838921.

12. Tan, H.T.; Ling, L.H.; Dolor-Torres, M.C.; Yip, J.W.; Richards, A.M.; Chung, M.C. Proteomics discovery of biomarkers for 391 mitral regurgitation caused by mitral valve prolapse. J Proteomics 2013, 94, 337-345, doi: 10.1016/j.jprot.2013.10.009

13. Hulanicka, M.; Garncarz, M.; Parzeniecka-Jaworska, M.; Jank, M. Plasma miRNAs as potential biomarkers of chronic 408 degenerative valvular disease in Dachshunds. BMC Vet Res 2014, 10, 205, doi:10.1186/s12917-014-0205-8. 
14. Li, Q.; Freeman, L.M.; Rush, J.E.; Laflamme, D.P. Expression Profiling of Circulating MicroRNAs in Canine Myxomatous 410 Mitral Valve Disease. Int J Mol Sci 2015, 16, 14098-14108, doi:10.3390/ijms160614098.

15. Bulent Vatan, M.; Kalayci Yigin, A.; Akdemir, R.; Tarik Agac, M.; Akif Cakar, M.; Aksoy, M.; Tatli, E.; Kilic, H.; Gunduz, H.; 412 Guzel, D., et al. Altered Plasma MicroRNA Expression in Patients with Mitral Chordae Tendineae Rupture. J Heart Valve Dis 2016, 25, 580-588.

16. Hayek E, Gring CN, Griffin BP. Mitral valve prolapse. Lancet 2005 ;365:507-18.

17. Delling, F.N. ; Vasan, R.S. Epidemiology and pathophysiology of mitral valve prolapse : new insights into disease 347 progression, genetics, and molecular basis. Circulation 2014, 129, 2158-2170, doi :10.1161/CIRCULATIONAHA.113.006702

18. Barlow, J.B. ; Pocock, W.A. Billowing, floppy, prolapsed or flail mitral valves ? Am J Cardiol 1985, 55, 501-502, 355 doi :10.1016/0002-9149(85)90402-3.

19. Freed LA, Levy D, Levine RA, et al. Prevalence and clinical outcome of mitral valve prolapse. N Engl J Med $1999 ; 341: 1-7$.

20. The changing spectrum of valvular heart disease pathology. In : Braunwald E, ed. Harrison's advances in cardiology. New York : McGraw-Hill, 2002 :317-23.

21. Avierinos JF, Inamo J, Grigioni F, Gersh B, Shub C, Enriquez-Sarano M. Sex differences in morphology and outcomes of mitral valve prolapse. Ann Intern Med $2008 ; 149$ :787-95.

22. Zoghbi WA, Enriquez-Sarano M, Foster E, et al. Recommendations for evaluation of the severity of native valvular regurgitation with two-dimensional and Doppler 
echocardiography. J Am Soc Echocardiogr

23. Lang, R.M. ; Adams, D.H. 3D echocardiographic quantification in functional mitral regurgitation. JACC Cardiovasc Imaging 370 2012, 5, 346-347,

doi: 10.1016/j.jcmg.2012.02.005.

24. Zeng X, Levine RA, Hua L, Morris EL, Kang Y, Flaherty M, Morgan NV, Hung J. Diagnostic value of vena contracta area in the quantification of mitral regurgitation severity by color Doppler 3D echocardiography. Circ Cardiovasc Imaging. 2011 Sep;4(5):506-13.

25. Carpentier, A. ; Chauvaud, S. ; Fabiani, J.N. ; Deloche, A. ; Relland, J. ; Lessana, A. ; D'Allaines, C. ; Blondeau, P. ; Piwnica, A. ; 357 Dubost, C. Reconstructive surgery of mitral valve incompetence : ten-year appraisal. J Thorac Cardiovasc Surg 1980, 79, 338358348.

26. Yacoub M, Halim M, Radley-Smith R, McKay R, Nijveld A, Towers M. Surgical treatment of mitral regurgitation caused by floppy valves : repair versus replacement.

Circulation 1981;64: II-210-II-216.

27. Verma S, Mesana TG. Mitral-valve repair for mitral-valve prolapse. N Engl J Med. 2009 Dec 3;361(23):2261-9

28. Feldman T, Kar S, Elmariah S, Smart SC, Trento A, Siegel RJ, Apruzzese P, Fail P, Rinaldi MJ, Smalling RW, Hermiller JB, Heimansohn D, Gray WA, Grayburn PA, Mack MJ, Lim DS, Ailawadi G, Herrmann HC, Acker MA, Silvestry FE, Foster E, Wang A, Glower DD, Mauri L; EVEREST II Investigators Randomized Comparison of Percutaneous Repair and Surgery for Mitral Regurgitation: 5-Year Results of EVEREST II. J Am Coll Cardiol. 2015 Dec 29;66(25):2844-2854. 
29. Nishimura, R.A.; Otto, C.M.; Bonow, R.O.; Carabello, B.A.; Erwin, J.P., 3rd; Fleisher, L.A.; Jneid, H.; Mack, M.J.; McLeod, 377 C.J.; O'Gara, P.T., et al. 2017 AHA/ACC Focused Update of the 2014 AHA/ACC Guideline for the Management of Patients With Valvular Heart Disease: A Report of the American College of Cardiology/American Heart Association Task Force on 379 Clinical Practice Guidelines. Circulation 2017, 135, e1159-e1195, doi:10.1161/CIR.0000000000000503

30. Falk V, Baumgartner H, Bax JJ, De Bonis M, Hamm C, Holm PJ, Iung B, Lancellotti P, Lansac E, Muñoz DR, Rosenhek R, Sjögren J, Tornos Mas P, Vahanian A, Walther T, Wendler O, Windecker S, Zamorano JL; ESC Scientific Document Group. 2017 EACTS Guidelines for the management of valvular heart disease. Eur J Cardiothorac Surg. 2017 Oct $1 ; 52(4): 616-664$

31. Carthew, R.W. ; Sontheimer, E.J. Origins and Mechanisms of miRNAs and siRNAs. Cell 2009, 136, 642-655, 393 doi: 10.1016/j.cell.2009.01.035

32. Songia P, Chiesa M, Alfieri V, Massaiu I, Moschetta D, Myasoedova V, Valerio V, Fusini L, Gripari P, Zanobini M, Poggio P Putative Circulating MicroRNAs Are Able to Identify Patients with Mitral Valve Prolapse and Severe Regurgitation. Int J Mol Sci. 2021 Feb 20;22(4):2102.

33. Deroyer, C. ; Magne, J. ; Moonen, M. ; Le Goff, C. ; Dupont, L. ; Hulin, A. ; Radermecker, M. ; Colige, A. ; Cavalier, E. ; Kolh, P., et al. New biomarkers for primary mitral regurgitation. Clin Proteomics 2015, 12, 25, doi :10.1186/s12014-015-9097-2.

34. Saporiti, F.; Piacentini, L.; Alfieri, V.; Bono, E.; Ferrari, F.; Chiesa, M.; Colombo, G.I. Melanocortin-1 Receptor Positively 426 Regulates Human Artery Endothelial Cell Migration. Cell Physiol Biochem 2019, 52, 1339-1360, doi:10.33594/000000094. 427 
35. Wylie-Sears, J.; Aikawa, E.; Levine, R.A.; Yang, J.H.; Bischoff, J. Mitral valve endothelial cells with osteogenic differentiation potential. Arterioscler Thromb Vasc Biol 2011, 31, 598-607, doi :10.1161/ATVBAHA.110.216184.

36. Rabkin, E. ; Aikawa, M. ; Stone, J.R. ; Fukumoto, Y. ; Libby, P. ; Schoen, F.J. Activated interstitial myofibroblasts express catabolic enzymes and mediate matrix remodeling in myxomatous heart valves. Circulation 2001, 104, 2525-2532, 431 doi $: 10.1161 /$ hc4601.099489. 432

37. Roberts, W.C. ; Vowels, T.J. ; Ko, J.M. ; Hebeler, R.F., Jr. Gross and histological features of excised portions of posterior mitral leaflet in patients having operative repair of mitral valve prolapse and comments on the concept of missing (= ruptured) chordae tendineae. J Am Coll Cardiol 2014, 63, 1667-1674, doi: 10.1016/j.jacc.2013.11.017. 435

38. Sainger, R. ; Grau, J.B. ; Branchetti, E. ; Poggio, P. ; Seefried, W.F. ; Field, B.C. ; Acker, M.A. ; Gorman, R.C. ; Gorman, J.H., 3rd ; Hargrove, C.W., 3rd, et al. Human myxomatous mitral valve prolapse : role of bone morphogenetic protein 4 in valvular interstitial cell activation. J Cell Physiol 2012, 227, 2595-2604, doi :10.1002/jcp.22999.

39. Chen, W. ; Yan, X. ; Yang, A. ; Xu, A. ; Huang, T. ; You, H. miRNA-150-5p promotes hepatic stellate cell proliferation and sensitizes hepatocyte apoptosis during liver fibrosis. Epigenomics 2020, 12, 53-67, doi :10.2217/epi-2019-0104. 443

40. Liu, F.; Di Wang, X. miR-150-5p represses TP53 tumor suppressor gene to promote proliferation of colon adenocarcinoma. Sci Rep 2019, 9, 6740, doi:10.1038/s41598019-43231-5. 445

41. Zhu, J. ; Han, S. miR-150-5p promotes the proliferation and epithelial-mesenchymal transition of cervical carcinoma cells via targeting SRCIN1. Pathol Res Pract 2019, 215, 738-747, doi: 10.1016/j.prp.2019.01.004 
42. Ryu J, Ahn Y, Kook H, Kim YK. The roles of non-coding RNAs in vascular calcification and opportunities as therapeutic targets. Pharmacol Ther. 2021 Feb; 218:107675.

43. Leopold JA. Vascular calcification: mechanisms of vascular smooth muscle cell calcification. Trends Cardiovasc Med. 2015; 25:267-74.

44. D'Amelio P, Isaia G, Isaia GC. The osteoprotegerin/RANK/RANKL system: a bone key to vascular disease. J Endocrinol Invest. 2009; 32:6-9.

45. Min H, Morony S, Sarosi I, Dunstan CR, Capparelli C, Scully S, Van G, Kaufman S, Kostenuik PJ, Lacey DL, Boyle WJ, Simonet WS. Osteoprotegerin reverses osteoporosis by inhibiting endosteal osteoclasts and prevents vascular calcification by blocking a process resembling osteoclastogenesis. J Exp Med. 2000; 192:463-74.

46. Agharazii M, St-Louis R, Gautier-Bastien A, Ung RV, Mokas S, Larivière R, Richard DE. Inflammatory cytokines and reactive oxygen species as mediators of chronic kidney disease-related vascular calcification. Am J Hypertens. 2015 Jun;28(6):746-55.

47. Du Y, Gao C, Liu Z, Wang L, Liu B, He F, Zhang T, Wang Y, Wang X, Xu M, Luo GZ, Zhu Y, Xu Q, Wang X, Kong W. Upregulation of a disintegrin and metalloproteinase with thrombospondin motifs-7 by miR-29 repression mediates vascular smooth muscle calcification. Arterioscler Thromb Vasc Biol. 2012 Nov;32(11):2580-8. doi: 10.1161/ATVBAHA.112.300206.

48. Balderman, J. A., Lee, H. Y.,Mahoney, C. E., Handy, D. E., White, K., Annis, S., ... Leopold, J. A. (2012). Bone morphogenetic protein-2 decreases microRNA-30b and microRNA-30c to promote vascular smooth muscle cell calcification. Journal of the American Heart Association 1, e003905. 
49. Liao, X. B., Zhang, Z. Y., Yuan, K., Liu, Y., Feng, X., Cui, R. R., ... Yuan, L. Q. (2013). MiR-133a modulates osteogenic differentiation of vascular smooth muscle cells. Endocrinology 154, 3344-3352.

50. R. R., Li, S. J., Liu, L. J., Yi, L., Liang, Q. H., Zhu, X., ... Liao, E. Y. (2012). MicroRNA204 regulates vascular smooth muscle cell calcification in vitro and in vivo. Cardiovascular Research 96, 320-329.

51. Qiao, W., Chen, L., \& Zhang, M. (2014). MicroRNA-205 regulates the calcification and osteoblastic differentiation of vascular smooth muscle cells. Cellular Physiology and Biochemistry 33, 1945-1953.

52. Lin, X., Zhan, J. K., Zhong, J. Y., Wang, Y. J.,Wang, Y., Li, S., ... Liu, Y. S. (2019). lncRNA-ES3/ miR-34c-5p/BMF axis is involved in regulating high-glucose-induced calcification/senescence of VSMCs. Aging (Albany NY) 11, 523-535.

53. Wei J, Shi Y, Zheng L, et al. miR-34s inhibit osteoblast proliferation and differentiation in the mouse by targeting SATB2. J Cell Biol. 2012;197(4):509-521. doi:10.1083/jcb.201201057

54. Hao J, Zhang L, Cong G, Ren L, Hao L. MicroRNA-34b/c inhibits aldosterone-induced vascular smooth muscle cell calcification via a SATB2/Runx2 pathway. Cell Tissue Res. 2016 Dec;366(3):733-746.

55. Ducy P., Schinke T., Karsenty G. 2000. The osteoblast: a sophisticated fibroblast under central surveillance. Science. 289:1501-1504 10.1126/science.289.5484.1501

56. Sudo, R., Sato, F., Azechi, T., \& Wachi, H. (2015). MiR-29-mediated elastin downregulation contributes to inorganic phosphorus-induced osteoblastic differentiation in vascular smooth muscle cells. Genes to Cells 20, 1077-1087.

57. Panizo, S., Naves-Diaz, M., Carrillo-Lopez, N., Martinez-Arias, L., Fernandez-Martin, J. L., Ruiz-Torres, M. P., ... Rodriguez, I. (2016). MicroRNAs 29b, 133b, and 211 
regulate vascular smooth muscle calcification mediated by high phosphorus. J Am Soc Nephrol 27, 824-834.

58. Pan W, Liang J, Tang H, Fang X, Wang F, Ding Y, Huang H, Zhang H. Differentially expressed microRNA profiles in exosomes from vascular smooth muscle cells associated with coronary artery calcification. Int J Biochem Cell Biol. 2020 Jan; 118:105645.

59. Ryu, J., Kwon, D. H., Choe, N., Shin, S., Jeong, G., Lim, Y. H., ... Kim, Y. K. (2019). Characterization of circular RNAs in vascular smooth muscle cells with vascular calcification. Molecular Therapy-Nucleic Acids 19, 31-41.

60. Sun R, Liu M, Lu L, Zheng Y, Zhang P. Congenital Heart Disease: Causes, Diagnosis, Symptoms, and Treatments. Cell Biochem Biophys. 2015 Jul;72(3):857-60.

61. Dolbec K, Mick NW. Congenital heart disease. Emerg Med Clin North Am. 2011 Nov;29(4):811-27, vii.

62. Higgins SS, Reid A. Common congenital heart defects. Long-term follow-up. Nurs Clin North Am. 1994 Jun;29(2):233-48.

63. Chen JF, Mandel EM, Thomson JM, Wu Q, Callis TE, Hammond SM, et al. The role of microRNA-1 and microRNA-133 in skeletal muscle proliferation and differentiation.Nature genetics. 2006;38(2):228-33.

64. Yin VP, Lepilina A, Smith A, Poss KD. Regulation of zebrafish heart regeneration by miR-133. Dev Biol. 2012; 365:319-327.

65. Porrello ER, Mahmoud AI, Simpson E, et al. Regulation of neona- tal and adult mammalian heart regeneration by the miR-15 family. Proc Natl Acad Sci USA. 2013; 110:187-192.

66. Eulalio A, Mano M, Dal Ferro M, et al. Functional screening iden- tifies miRNAs inducing cardiac regeneration. Nature. 2012;492: 376-381. 
67. Wojciechowska A, Braniewska A, Kozar-Kamińska K. MicroRNA in cardiovascular biology and disease. Adv Clin Exp Med. 2017 Aug;26(5):865-874.

68. Yoshida T, Delafontaine P. Mechanisms of IGF-1-Mediated Regulation of Skeletal Muscle Hypertrophy and Atrophy. Cells. 2020 Aug 26;9(9):1970.

69. Zhou H, Wang B, Yang YX, Jia QJ, Zhang A, Qi ZW, Zhang JP. Long Noncoding RNAs in Pathological Cardiac Remodeling: A Review of the Update Literature. Biomed Res Int. 2019 Jul 1; 2019:7159592.

70. C.A. Simmons, J. Zilberberg, P.F. Davies, A rapid, reliable method to isolate high quality endothelial RNA from small spatially-defined locations, Ann. Biomed. Eng.32 (2004) 1453-1459.

71. C.A. Simmons, G.R. Grant, E. Manduchi, P.F. Davies, Spatial heterogeneity of endothelial phenotypes correlates with side-specific vulnerability to calcification in normal porcine aortic valves, Circ. Res. 96 (2005) 792-799, https://doi.org/10.1161/01.res.0000161998.92009.64.

72. Scolari FL, Faganello LS, Garbin HI, Piva E Mattos B, Biolo A. A systematic review of microRNAs in patients with hypertrophic cardiomyopathy. Int J Cardiol. 2021 Mar 15;327:146154.

73. A.V. Villar, D. Merino, M. Wenner, M. Llano, M. Cobo, C. Montalvo, R. Garc a, R. Mart n-Dur n, J.M. Hurl , M.A. Hurl , J.F. Nistal, Myocardial gene expression of microRNA-133a and myosin heavy and light chains, in conjunction with clinical parameters, predict regression of left ventricular hypertrophy after valve replacement in patients with aortic stenosis, Heart 97 (2011) 1132-1137, https://doi.org/ 10.1136/hrt.2010.220418.

74. R. Garc a, A.V. Villar, M. Cobo, M. Llano, R. Mart n-Dur n, M.A. Hurl , J.F. Nistal, Circulating levels of miR-133a predict the regression potential of left ventricular hypertrophy after valve replacement surgery in patients with aortic stenosis, J. Am. Heart Assoc. 2 (2013) e000211, , https://doi.org/10.1161/JAHA.113.000211. 
75. S. Rathan, C.J. Ankeny, S. Arjunon, Z. Ferdous, S. Kumar, J. Fernandez Esmerats, et al., Identification of side- and shear-dependent microRNAs regulating porcine aortic valve pathogenesis, Sci. Rep. 6 (2016) 25397, , https://doi.org/10.1038/srep25397.

76. J.M. Heath, J. Fernandez Esmerats, L. Khambouneheuang, S. Kumar, R. Simmons, H. Jo, Mechanosensitive microRNA-181b regulates aortic valve endothelial matrix degradation by targeting TIMP3, Cardiovasc. Eng. Technol. (2017), https://doi.org/10.1007/s13239-017-0296-z Epub 2017/02/27.

77. X. Sun, B. Icli, A.K. Wara, N. Belkin, S. He, L. Kobzik, et al., MicroRNA-181b regulates NF-kappaB-mediated vascular inflammation, J. Clin. Invest. 122 (2012)19731990, https://doi.org/10.1172/jci61495.

78. Larivière R, Gauthier-Bastien A, Ung RV, St-Hilaire J, Mac-Way F, Richard DE, Agharazii M. Endothelin type A receptor blockade reduces vascular calcification and inflammation in rats with chronic kidney disease. J Hypertens. 2017 Feb;35(2):376384.

79. Wu SY, Zhang BH, Pan CS, Jiang HF, Pang YZ, Tang CS, Qi YF. Endothelin-1 is a potent regulator in vivo in vascular calcification and in vitro in calcification of vascular smooth muscle cells. Peptides. 2003 Aug;24(8):1149-56.

80. Henein, M., Gran sen, G., Wiklund, U., Schmermund, A., Guerci, A., Erbel, R., \& Raggi, P. (2015). High dose and long-term statin therapy accelerate coronary artery calcification. International Journal of Cardiology 184, 581-586.

81. Ling, H., Fabbri, M., \& Calin, G. A. (2013). MicroRNAs and other non-coding RNAs as targets for anticancer drug development. Nature Reviews. Drug Discovery 12, 847865.

82. Toshima T, Watanabe T, Narumi T, Otaki Y, Shishido T, Aono T, Goto J, Watanabe K, Sugai T, Takahashi T, Yokoyama M, Kinoshita D, Tamura H, Kato S, Nishiyama S, 
Arimoto T, Takahashi H, Miyamoto T, Sadahiro M, Watanabe M. Therapeutic inhibition of microRNA-34a ameliorates aortic valve calcification via modulation of Notch1-Runx2 signalling. Cardiovasc Res. 2020 Apr 1;116(5):983-994.

83. Wang Y, Han D, Zhou T, Zhang J, Liu C, Cao F, Dong N. Melatonin ameliorates aortic valve calcification via the regulation of circular RNA CircRIC3/miR-204-5p/DPP4 signaling in valvular interstitial cells. J Pineal Res. 2020 Sep;69(2):e12666.

84. van der Ven CF, Wu PJ, Tibbitt MW, van Mil A, Sluijter JP, Langer R, Aikawa E. In vitro 3D model and miRNA drug delivery to target calcific aortic valve disease. Clin Sci (Lond). 2017 Feb 1;131(3):181-195.

85. Ebert, M.S., Neilson, J.R. and Sharp, P.A. (2007) MicroRNA sponges: competitive inhibitors of small RNAs in mammalian cells. Nat. Methods 4, 721-726

86. Thum, T., Gross, C., Fiedler, J., Fischer, T., Kissler, S., Bussen, M., Galuppo, P., Just, S., Rottbauer, W., Frantz, S. et al. (2008) MicroRNA-21 contributes to myocardial disease by stimulating MAP kinase signalling in fibroblasts. Nature 456, 980-984

87. Ma, L., Reinhardt, F., Pan, E., Soutschek, J., Bhat, B., Marcusson, E.G., TeruyaFeldstein, J., Bell, G.W. and Weinberg, R.A. (2010) Therapeutic silencing of miR-10b inhibits metastasis in a mouse mammary tumor model. Nat. Biotechnol. 28, 341-347

88. Davis, S., Lollo, B., Freier, S. and Esau, C. (2006) Improved targeting of miRNA with antisense oligonucleotides. Nucleic Acids Res. 34, 2294-2304

89. Alexis, F., Pridgen, E., Molnar, L.K. and Farokhzad, O.C. (2008) Factors affecting the clearance and biodistribution of polymeric nanoparticles. Mol. Pharm. 5, 505-515

90. Kanasty, R.L., Whitehead, K.A., Vegas, A.J. and Anderson, D.G. (2012) Action and reaction: the biological response to siRNA and its delivery vehicles. Mol. Ther. 20, 513524 
91. Whitehead KA Langer R Anderson DG Knocking down barriers: advances in siRNA delivery. Nat Rev Drug Discov. 2009; 8: 129-138

92. Ameres SL, Obernosterer G, Gebeshuber CA, Schroeder R, Martinez J, et al. The impact of target site accessibility on the design of effective siRNAs. Nat Biotechnol. 2008; 26: 578-583

93. Davis, M., Chen, Z. \& Shin, D. Nanoparticle therapeutics: an emerging treatment modality for cancer. Nat Rev Drug Discov 7, 771-782 (2008). https://doi.org/10.1038/nrd2614

94. Chen, M. Y. et al. Surface properties, more than size, limiting convective distribution of virus-sized particles and viruses in the central nervous system. J. Neurosurg. 103, $311-319$ (2005)

95. Bartlett, D. W. \& Davis, M. E. Physicochemical and biological characterization of targeted, nucleic acid-containing nanoparticles. Bioconjug. Chem. 18, 456-468 (2007).

96. Hong, S. et al. The binding avidity of a nanoparticle-based multivalent targeted drug delivery platform. Chem. Biol. 14, 107-115 (2007).

97. Malam Y, Loizidou M, Seifalian AM. Liposomes and nanoparticles: nanosized vehicles for drug delivery in cancer. Trends Pharmacol Sci. 2009 Nov;30(11):592-9.

98. Allen TM, Cullis PR. Liposomal drug delivery systems: from concept to clinical applications. Adv Drug Deliv Rev. 2013 Jan;65(1):36-48.

99. Abu Lila AS, Ishida T. Liposomal Delivery Systems: Design Optimization and Current Applications. Biol Pharm Bull. 2017;40(1):1-10.

100. Barile L, Vassalli G. Exosomes: Therapy delivery tools and biomarkers of diseases. Pharmacol Ther. 2017 Jun; 174:63-78. 
101. van Rooij T, Luan Y, Renaud G, van der Steen AF, Versluis M, de Jong N,

Kooiman K. Non-linear response and viscoelastic properties of lipid-coated microbubbles: DSPC versus DPPC. Ultrasound Med Biol. 2015 May;41(5):1432-45.

102. Langeveld SAG, Beekers I, Collado-Lara G, van der Steen AFW, de Jong N, Kooiman K. The Impact of Lipid Handling and Phase Distribution on the Acoustic Behavior of Microbubbles. Pharmaceutics. 2021 Jan 19;13(1):119.

103. Daeichin V, van Rooij T, Skachkov I, Ergin B, Specht PA, Lima A, Ince C, Bosch JG, van der Steen AF, de Jong N, Kooiman K. Microbubble Composition and Preparation for High-Frequency Contrast-Enhanced Ultrasound Imaging: In Vitro and In Vivo Evaluation. IEEE Trans Ultrason Ferroelectr Freq Control. 2017 Mar;64(3):555-567.

104. Upadhyay A, Dalvi SV, Gupta G, Khanna N. Effect of PEGylation on performance of protein microbubbles and its comparison with lipid microbubbles. Mater Sci Eng C Mater Biol Appl. 2017 Feb 1; 71:425-430.

105. Gilam, A., Conde, J., Weissglas-Volkov, D. et al. Local microRNA delivery targets Palladin and prevents metastatic breast cancer. Nat Commun 7, 12868 (2016)

106. Conde, J., Oliva, N. \& Artzi, N. Implantable hydrogel embedded dark-gold nanoswitch as a theranostic probe to sense and overcome cancer multidrug resistance. Proc. Natl Acad. Sci. USA 112, E1278-E1287 (2015).

107. Segovia, N. et al. Hydrogel doped with nanoparticles for local sustained release of siRNA in breast cancer. Adv. Healthc. Mater. 4, 271-280 (2015).

108. Conde, J., Oliva, N., Atilano, M., Song, H. S. \& Artzi, N. Self-assembled RNAtriple-helix hydrogel scaffold for microRNA modulation in the tumour microenvironment. Nat. Mater. 15, 353-363 (2016). 
109. Rita Balistreri C, Allegra A, Crapanzano F, Pisano C, Ruvolo G. Matrix Metalloproteinases (MMPs), Their Genetic Variants and miRNA in Mitral Valve Diseases: Potential Biomarker Tools and Targets for Personalized Treatments. J Heart Valve Dis. 2016 Jul;25(4):463-474.

110. Chen A, Wen J, Lu C, Lin B, Xian S, Huang F, Wu Y, Zeng Z. Inhibition of miR-155-5p attenuates the valvular damage induced by rheumatic heart disease. Int $\mathbf{J}$ Mol Med. 2020 Feb;45(2):429-440. 